\title{
Subjective Perception of Radiation Risk
}

\author{
Lutz S. Freudenberg ${ }^{1,2}$ and Thomas Beyer ${ }^{1,3}$ \\ ${ }^{I}$ Department of Nuclear Medicine, University Hospital Essen, Essen, Germany; ${ }^{2}$ Department of Nuclear Medicine, \\ ZRN Grevenbroich, Grevenbroich, Germany; and ${ }^{3}$ cmi-experts GmbH, Zurich, Switzerland
}

Physicians, medical staff, and patients, much like the general population, are becoming increasingly sensitized to the issue of radiation exposure from diagnostic or therapeutic procedures. The attitudes of patients undergoing diagnostic imaging procedures that use ionizing radiation vary widely. Patient perception of radiation dose strongly influences their acceptance of diagnostic examinations or therapies involving radioactivity. Here, we review perceptions and concerns about radiation and radioactivity by laypersons and medical experts. Several studies show that physicians are frequently poorly informed about radiation levels associated with nuclear medicine and radiologic examinations. In addition, patients' decisions against undergoing an imaging procedure are frequently based on partial and sometimes incorrect information. Thus, physicians must take the concerns of their patients seriously. From the literature and our own experience, we conclude that it is extremely important to thoroughly and carefully educate all involved in patient work-up about radiation exposure levels and perceived or actual health risks. Although the choice and timing of imaging examinations should always outweigh the risk that secondary illness will develop, the patients' concerns still must be alleviated.

Key Words: nuclear medicine; patient perception; radiation risk; radiology

J Nucl Med 2011; 52:29S-35S

DOI: 10.2967/jnumed.110.085720

$\mathbf{R}$ adiologic and nuclear medical imaging studies are essential diagnostic tools and thus form the basis for many therapeutic decisions. Diagnostic imaging relies mainly on ionizing radiation, and nearly half of the average radiation exposure of the general public can be ascribed to medical procedures. The largest portion of radiation exposure is contributed by radioactive materials and ionizing radiation, especially X-rays (1-4). A study by Fazel et al. (1) demonstrated that in the United States between 2005 and 2007, CT and nuclear imaging accounted for $21 \%$ of imaging procedures and $75 \%$ of the total effective manufactured

Received Feb. 19, 2011; revision accepted Aug. 22, 2011.

For correspondence or reprints contact: Lutz S. Freudenberg, Department of Nuclear Medicine, University Hospital Essen, Hufelandstrasse 55, 45122 Essen, Germany.

E-mail: lutz.freudenberg@uni-due.de

COPYRIGHT @ 2011 by the Society of Nuclear Medicine, Inc. radiation dose. In contrast, plain radiography accounted for $71 \%$ of all imaging procedures but only $11 \%$ of the total effective dose. In Germany in 2006, the radiation exposure of the public averaged $1.8 \mathrm{mSv}$ for X-ray diagnostics and $0.13 \mathrm{mSv}$ for nuclear medicine (3). In particular, during the last few decades, there has been a significant increase in the average number of CT scans per person (3).

The increased frequency of radiology imaging examinations worldwide has triggered studies on the lifetime risk of cancer from external radiation exposure-studies that are discussed controversially (5-7). Calculations of cancer risk from diagnostic work-ups using imaging techniques based on sources of ionizing radiation predict numbers of cancer cases ranging in the thousands for patients in industrialized countries. For example, Berrington de González et al. (8) expected that in the United States, approximately 29,000 cancer cases (95\% uncertainty limits, 15,000-45,000) will arise that are related to CT scans performed in 2007. Brenner and Hall estimated that $0.4 \%$ of all cancers in the United States may be attributable to CT (5). A recent report by the Medical Board of the Health Authorities in Zurich, Switzerland, referred to combined PET/CT as an "imaging examination with maximum radiation exposure and potential harm" and thus "posing a certain risk to the patient of developing cancer from the examination" (9).

Although the objectivity of lay reports can be fairly easily disputed, reviews of dose-related risks deserve more attention. Eschner et al. pointed out that calculations of cancer risk from radiation exposure typically neglect the fact that exposure is not evenly spread across the studied subjects, not even across subgroups of a given age range (10). Therefore, a major proportion of the total dose from medical imaging examinations does not constitute a risk for developing cancer. This situation can be explained by the poorer overall prognosis of patients than of nonpatients of the same sex and age group. Consequently, the choice and timing of the most efficacious imaging examination always outweigh the risk to the patient of developing cancer (11).

Nevertheless, patients are increasingly sensitive to the question of radiation risk. Patients range from underestimating the risks (12) to rejecting the tests even at the risk of deleterious health outcomes (13). When paired with lack of knowledge of the benefits of medical imaging and lack of understanding of the effects of ionizing radiation, this sensitivity to possible risk and rejection of tests may 
lead to inappropriate diagnostic and clinical decisions. In the present review, we reflect on medical, sociologic, and cultural studies that investigate patient concerns and attitudes about ionizing radiation. We include data from a standard literature search using PubMed, as well as from full-text searches in the cultural and sociologic online archives JSTOR (Journal STORage, http://www.jstor.org/) and MUSE (http://muse.jhu.edu/). Drawing on the results of the selected studies, we offer suggestions on how to address the concerns of patients, and we propose corresponding actions with regard to therapeutic decisions.

\section{EXPERTS AND LAYPERSONS LIVE ON DIFFERENT PLANETS}

Since the 1970s, it has been known that there are significant differences between the way laypersons and experts judge ionizing radiation. For example, laypersons see a high risk potential in nuclear energy and regard this power source as unacceptable but believe that X-rays have a low risk and hence are acceptable (14). By contrast, experts describe both nuclear energy and X-rays as acceptable and assert that both bear a moderate health risk $(14,15)$. Nonexperts and experts agree only in their assessment of the danger potential of nuclear weapons (16). Moreover, there is no uniform or consistent perception of radiation risks (17).

Recent studies by Ludwig and Turner confirmed this observation. In a survey that included 200 laypersons, the assessment of radiation risk matched that of experts in only $50 \%$ of respondents (18). Comparable differences in risk perception have also been described in radiation therapy (19,20).

Investigations during which dichotomous risk qualities were to be allocated to different kinds of radiation showed similar results $(17,21)$. The authors concluded in reference to risk perceptions that "some conflicts over 'risk' may result from experts and lay people having different definitions of the concept." (21).

Here, a conflict between subjective lay knowledge and objective expert knowledge emerges that can be resolved only with difficulty through a purely scientific approach (22). When patients are asked to make a decision for or against a certain therapy, the discrepancy between their opinions and those of the experts may ultimately result in patients refusing a medically indicated procedure. Alternatively, patients may agree to the procedure reluctantly and undergo it uncooperatively.

\section{CONCEPTS OF NON-MEDICAL PROFESSIONALS}

\section{An Approach to Understanding Attitudes}

The medical professional has to be methodically openminded to understand the perceptions of laypersons. The implicit association test developed by Greenwald et al. (23) is an interesting approach used in social psychology. The test measures the strength of associations between mental representations of objects in memory. It is based on the idea that during a computer-based experiment, it is easier to use the same response key for associated concepts instead of the opposite key (24).

The implicit association test, which is administered mainly to measure implicit attitudes toward objects or stereotypes, was used, for example, in a Swiss study to investigate personal attitudes toward nuclear energy and the electromagnetic radiation of mobile phones (25). The negative attitudes that were found by the test were stronger than those simultaneously submitted by the subjects in written questionnaires. However, the question of the meanings and context is not answered. A combined qualitative and quantitative method is a possible way to address this issue.

The quantitative approach - the foundation of all scientific research-is guided by measurable objective observations that can be expressed via formulas. In the context of cultural studies or sociology, quantitative research results often remain on the surface because numerous factors, in particular social, societal, and cultural, are omitted. Because the complexity of many situations cannot be expressed numerically, a purely quantitative approach might not be applicable to daily life situations and thus might lack practical relevance (26-28).

The qualitative research approach aims at investigating and understanding a research area using an open method. The researchers present, in conjunction with the data, an individual framework of meaning and interpretation. Thus, the qualitative approach is particularly attractive for analyses in cultural studies because in this discipline, observations are based on realities that have already been interpreted (29). Here, subjective assessments by the subjects under study strongly shape their notion of reality. Simultaneously, different social areas are integrated by being united within a single person. Thus, new connections and correlations between different areas can be recognized, unlike the case in a purely quantitative approach (27).

The qualitative method offers several solid research approaches, such as content analysis $(30,31)$; its goal is to analyze the argumentative and practical structure of opinions (26). In other words, during the analysis the opinion of the person in question will be assessed systematically. The qualitative approach is judged critically with respect to its methods and the representativeness of its results $(28,32)$.

\section{CT}

In recent years, radiation exposure during $\mathrm{CT}$ procedures has become increasingly scrutinized by the scientific community and the general population. This increased scrutiny is due to the great increase in the use of CT since the inception of the modality in the 1970s (5). For example, in the United States the annual number of CT examinations increased from about 3.6 million in 1980 to 13.3 million in 1990 and 33 million in 1998. In 1980, when CT accounted for less than $3 \%$ of all radiologic examinations, it contributed to $5 \%$ of the accumulated dose of all X-ray procedures (4). Today in the Western world, CT accounts for about $15 \%$ of radiology procedures performed across all medical 
settings and contributes up to $75 \%$ of the medically administered radiation dose $(33,34)$ and up to $40 \%$ of the total radiation dose (4). It is clear that CT is a key diagnostic imaging examination warranted for numerous clinical indications. Nonetheless, there is growing concern that CT is being overused $(5,35)$. Overuse of a clinical method needs to be judged by cost-benefit calculations, and measures to prevent overuse may vary by country and even medical specialty (36). Other concerns about overexposure stemming from overuse may be addressed to a great extent by adopting optimized imaging protocols and dose reduction schemes (11), which require standardization and inclusion in imaging guidelines.

In this context, it is interesting to point to studies that assessed the understanding of nonradiologist professionals ordering CT examinations. Lee et al. noted from a survey conducted at an academic imaging center in 2004 that all surveyed participants underestimated the radiation exposure from a CT examination relative to a plain radiograph of the thorax (37). Interestingly, only $22 \%$ of the interviewed emergency department physicians and $13 \%$ of the interviewed radiologists estimated the dose from the CT scan correctly. The same observation was made by Heyer et al. (38) when assessing the knowledge of nonradiologic physicians with an average clinical experience of 8 y concerning radiation exposure during radiologic procedures on the thorax; only $34 \%$ correctly estimated the effective dose from a thoracic CT scan.

However, no qualitative study has investigated the subjective perception of CT by patients. We believe that this is due to the immediate integration of CT into the work-up of patients with a multitude of diseases: patients simply expect that a CT scan will be performed. In a study that included 1,168 patients with abdominal pain, Baumann et al. showed that most patients expressed a low level of confidence in medical evaluations that were limited to a physicianconducted history and a physical examination (12). Patients with abdominal pain expect some type of laboratory or radiologic testing, as evidenced by a nearly 4-fold increase in patient confidence level with just the addition of blood work to a physician-conducted history and physical examination, and the highest level of confidence when the medical evaluation included a CT scan (12).

Patients appear more confident when CT is part of their medical evaluation but have a poor understanding of the concomitant radiation exposure and risk, and they have a poor understanding of the concomitant radiation exposure and risk associated with the CT scan, or with previous Xray imaging examinations they may have passed. This suggests that patient perception is not necessarily an impediment to the use of radiation.

\section{Diagnostic Nuclear Medicine}

Diagnostic nuclear medicine is another field that has not been analyzed systematically from the perspective of patient perception. The only exceptions are 2 Dutch studies that discussed the emotional strain patients felt from various diagnostic tests, including CT and PET $(39,40)$. The average strain for all tests in both studies was low, suggesting that the diagnostic work-up is not significantly influenced by these factors $(39,40)$. However, small but significant differences in patient strain were observed for imaging tests to assess esophageal cancer (39). The perceived stress associated with the PET examination was lower than that of endoscopic ultrasonography. More than half the melanoma patients experienced no strain during the PET study, 65\% experienced no strain during CT, and $80 \%$ experienced no strain during chest radiography; both studies revealed "more emotional discomfort during the PET examination than during the CT study." Both studies pointed out that the reasons for this stress pattern can be found in the long examination times needed for the PET-only systems. When PET/CT with examination times of only 20 min or less is used, the strain level associated with PET/CT is likely to be similar to that from a CT examination. However, this hypothesis needs to be confirmed in future studies.

Medical and technical staff can easily reflect on whether their conduct and attitudes contribute positively toward how the patient perceives the imaging examination and, thus, toward patient cooperation. For example, patients felt embarrassment and discomfort when they had not been sufficiently informed about the procedure or were asked to wait in a cold environment (40).

\section{Radioactivity and Therapy}

Although there are relatively few data on perceptions about radiation in the area of radiologic and nuclear medical diagnostics, significantly more data are available for nuclear medicine therapies, particularly radioiodine therapy (RIT).

A couple of combined qualitative and quantitative studies revealed a wide spectrum of patient perceptions, which frequently did not reflect scientific views (41-45). The qualitative research was performed using open interviews that were transcribed and then were analyzed by reducing and consolidating the main information from the transcribed text (content analysis). As such, certain key words were extracted and categorized from the interviews. Thereafter, 2 additional analysis methods were used: frequency analysis and valence analysis, the first being based on a descriptive counting of individual mentions of a factor and the latter taking the frequency analysis further by asking whether the mentioned factor had a positive or negative connotation. Such an analysis of interviews conducted on 68 patients before a possible RIT (44) showed that respondents evaluated radioactivity overall as negative (Table 1). This result reflects a high level of uncertainty and distrust.

In another study, Erikson et al. showed that the fear of contamination is perceived as threatening because radiation is not a sensory experience (46). The exposure to radioactivity, for example, occurs in a way that Eriksson in a different paper described as follows: "contaminate rather than merely damage...pollute. Befoul, and taint rather than just 
TABLE 1

Qualitative Evaluations of Radioactivity in Content Analysis According to Study by Freudenberg et al. (44)

\begin{tabular}{|c|c|}
\hline Attribute & Percentage $(n=68)$ \\
\hline \multicolumn{2}{|l|}{ Negative } \\
\hline Fear of dangers of nuclear energy & $84 \%$ \\
\hline Fear of malignant diseases & $78 \%$ \\
\hline Diffuse feeling of threat & $72 \%$ \\
\hline Fear of contamination & $53 \%$ \\
\hline Fear of changes of DNA & $21 \%$ \\
\hline Distrust in institutions & $16 \%$ \\
\hline Fear of death & $6 \%$ \\
\hline \multicolumn{2}{|l|}{ Neutral } \\
\hline A source of energy & $28 \%$ \\
\hline Mutations & $4 \%$ \\
\hline Cosmic/natural radiation & $3 \%$ \\
\hline \multicolumn{2}{|l|}{ Positive } \\
\hline Medical benefit & $75 \%$ \\
\hline Secure source of energy & $37 \%$ \\
\hline Source of evolution, hormesis & $6 \%$ \\
\hline
\end{tabular}

create wreckage...penetrate human tissue indirectly rather than wound the surface by assaults of a more straightforward kind." (47).

Furthermore, when describing radioactivity, patients repeatedly recall and describe the same images: the explosion of a nuclear bomb or the destroyed reactor in Chernobyl are part of the standard repertoire of the interviews. Weart (48), Smith (49), and Erikson $(46,47)$ argued that these images influence how technology itself is perceived. In this particular case, the influence is particularly strong because in the context of radioactivity, most images communicate the idea that "technology runs amok," as Hendee put it (50).

A radiation therapy study that also used a qualitative research approach revealed a similar tendency. However, in that study, during the "fight against cancer," mainly military images and metaphors came into focus (51); this association has also been described in cultural studies (52) and is promoted by many marketing approaches that catch the attention of the media.

Additionally, patients have a noticeable tendency to share their anxieties primarily in jokes that build on metaphors of fluorescence, such as in the question "Will I glow in the dark after my RIT?" (53). There appears to be a desire to create a sensory experience, which also presents the question of how the body is perceived as the "carrier substance" for radiation (54). These attitudes match the results of a methodologically weak study with preassigned categories that was conducted in the 1970s in German-speaking countries (55); $85 \%$ of the 181 randomly chosen administrators referred to X-rays as being dangerous (Table 2).

The results in Table 2 reveal the shortcomings of a purely quantitative approach because the categories for the answers were predetermined and for that reason reflect a scientific perspective. This explains why 4 of the 6 categories of the
TABLE 2

Assessment of Danger of X-Rays and Categorization of Negative Qualities of Radiation According to Study by Stegie et al. (55)

\begin{tabular}{lc}
\hline \multicolumn{1}{c}{ Factor } & Percentage $(n=181)$ \\
\hline Assessment of X-rays & $16 \%$ \\
Harmless & \\
Somewhat dangerous & $55 \%$ \\
Quite dangerous & $21 \%$ \\
Very dangerous & $9 \%$ \\
Categorization of negative qualities & $32 \%$ \\
$\quad$ Harmful influence on DNA & $19 \%$ \\
Destruction of cells and tissue & $19 \%$ \\
Burns & $11 \%$ \\
Generation of cancer & $5 \%$ \\
Radioactivity & $3 \%$ \\
Changes of blood count & $10 \%$ \\
Other & \\
\hline
\end{tabular}

qualitative study by Freudenberg et al. (44) (Table 1) were not included in the study by Stegie et al. (55) (Table 2).

\section{RIT}

When patients see a direct health benefit-for example through RIT - they significantly modify their generally negative assessment of radioactivity $(45,46)$. In a study by Freudenberg et al. (45), patients undergoing RIT were asked to grade their subjective perception of radioactivity in general and with respect to RIT in particular on a scale from 1 to 5 ( 1 = positive, $2=$ rather positive, $3=$ neutral, $4=$ rather negative, 5 negative). Figure 1 summarizes the results of this study, which demonstrated a trend toward a more positive perception of radioactivity after completing an RIT. Slovic (17) reached similar conclusions although he was unable to quantify this phenomenon.

Patients who received RIT also became more positive in their view of this treatment during long-term follow-up (45). This finding was also confirmed by a quantitative

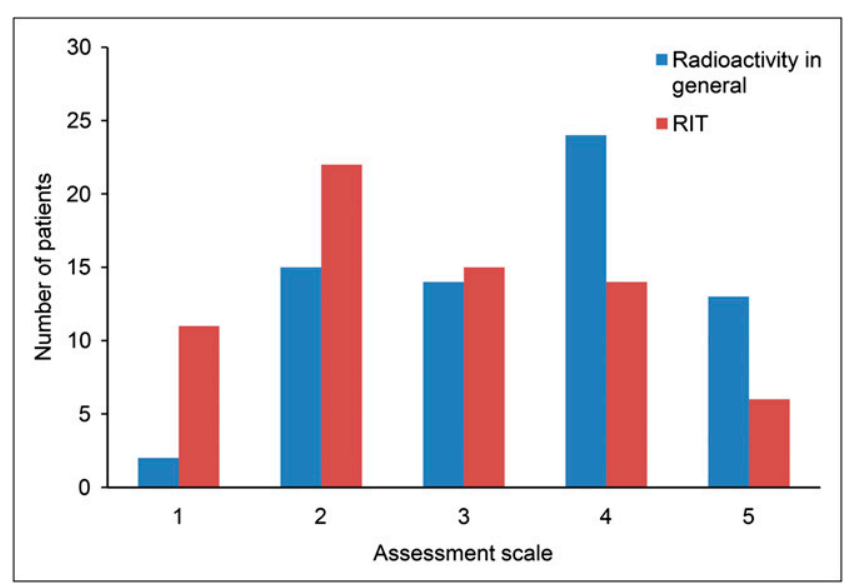

FIGURE 1. Subjective patient perception of radioactivity on a scale of $1-5(n=68)(1=$ positive, $2=$ rather positive, $3=$ neutral, $4=$ rather negative, and $5=$ negative). Changes with means of 3.5 (general) and 2.7 (RIT) are statistically significant $(P=0.01)$ (44). 
analysis (Fig. 2). This result was largely explained by patients' satisfaction with the outcome of RIT. However, it is noticeable that the general concept of radioactivity did not significantly change the attitude of the patients and that their generally negative attitude remained. In the context of the generally positive experiences that patients had with RIT, this result indicates that the patients' personal benefit seems to be dissociated from their general ideas about radiation. Slovic (17) and Weart (48) reported similar observations, which also corresponded to the results of numerous cultural studies (56-58).

\section{MISCONCEPTIONS AMONG NON-NUCLEAR MEDICINE CLINICIANS AND MEDICAL STUDENTS}

Knowing the reasoning of patients can be helpful when providing them with relevant information either while establishing the diagnosis or during therapy. Unfortunately, students and physicians seem to share with patients uncertainties about the effect of ionizing radiation (or radiation protection).

For example, a study group from Pakistan (59) documented that medical students at the end of their training gravely misjudged diagnostic procedures. "Slightly more than one-third of the students considered gamma rays more hazardous than X-rays while the same percentage agreed that intravenous contrast material used in angiograms was radioactive. Sixty-seven percent of the students agreed that nuclear materials used in medicine are potentially explosive, whereas $18 \%$ of students had the opinion that MRI emits ionizing radiation." (59). These misconceptions should be of concern to all of us, because they shape the ideas of future physicians who will promote their "professional" concepts that serve as "opinion multipliers" among patients.

Several studies have addressed the issue of dose awareness, or the lack thereof, among medical professionals. Heyer et al. showed in their survey of nonradiologic physicians that $8 \%$ of

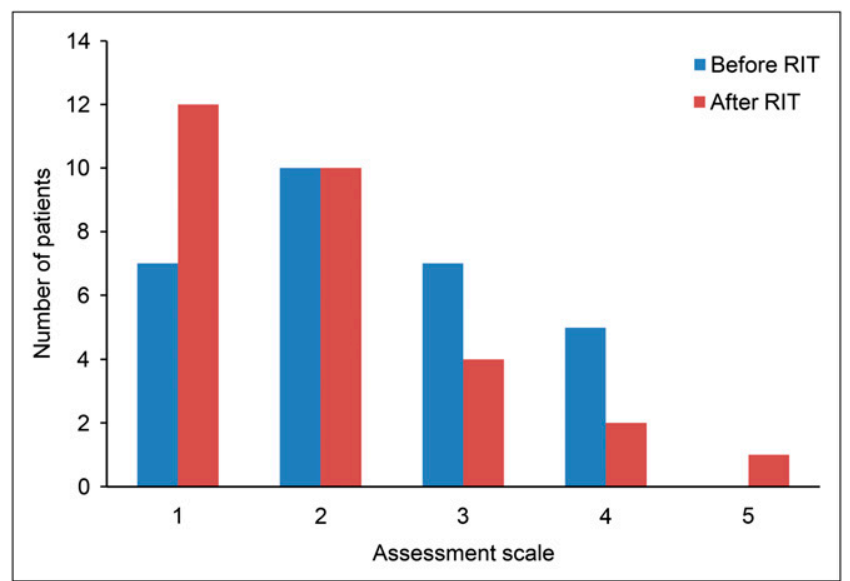

FIGURE 2. Subjective patient perception of radioactivity on a scale of $1-5$ before and after RIT $(n=29)(1=$ positive, $2=$ rather positive, $3=$ neutral, $4=$ rather negative, and $5=$ negative). Changes with means of 2.3 and 2.0 before and after RIT, respectively, are statistically significant $(P=0.03)(45)$. responders believed exposure of patients to radiation from an MRI scan was higher than that from a low-dose thoracic CT scan, thus awarding, as the authors of the study so eloquently put it, "for the first time an effective dose to MRI" (38). In a series of interviews with physicians by Gower-Thomas (60), only $2 \%$ of the interviewees were able to correctly answer more than $50 \%$ of the questions on approximate doses of radiation. The only reason that many physicians were able to respond correctly to any questions was because they realized that ultrasound examinations do not use ionizing radiation. The degree of knowledge was inversely proportional to seniority, with consultants scoring lower than junior colleagues. On a positive note, another survey confirmed that appropriate training does increase awareness about radiation doses among medical professionals (34).

This observation supports the need to educate non-nuclear medicine clinicians about ionizing radiation relevant to medical imaging, given their legal responsibility as referrers under the ionizing radiation regulations and their clinical role of providing accurate information to their patients.

\section{UTILIZING KNOWLEDGE ABOUT THE REASONING OF PATIENTS}

Patients have the right to receive adequate information before undergoing diagnostic and therapeutic procedures involving ionizing radiation, and they may rightfully demand to know the facts. Before the radiologic procedure, the topic of ionizing radiation should be part of the conversation between the physician and the patient. In general, there seems to be a high acceptance of diagnostic procedures. Patients do not seem to regard the risk as high and seem to care more about receiving a diagnosis for their condition than about theoretic considerations. Conversely, some patients perceive the risk of radiation as so high that they forgo critical diagnostic procedures.

In nuclear medicine, the situation is somewhat different, particularly as there may be alternative treatments available, such as in the case of RIT. Because the reasoning of patients can significantly influence the therapeutic decision, it is important to address patient perceptions early. As odd as the patients' mental associations and concepts may seem to the information-imparting physician $(50,61)$, these thoughts form the subjective reality of the patient and are, for that reason, the basis for the patient's decision for or against a therapy (42).

Knowing the concepts described above allows one to optimize preprocedural conversations with patients: for example, one could try to more thoroughly address the jokes and metaphors a patient uses. These not only are an expression of deeper anxieties but also may be the basis for a therapeutic decision. A typical standardized preprocedural discussion as used in other medical settings cannot be applied in this setting because of the complexity of the situation. Perhaps one could build on the experiences of radiation therapy groups that, as a result of patient-centered qualitative research, attempt to optimize physicians' strategies for delivering information $(62,63)$. For example, 
information can be provided in consecutive steps rather than en bloc (62). Furthermore, the psychologic factors noted during the conversation come into play (64). For these reasons, standardization is not appropriate for preprocedure conversations with patients. To the contrary, an individualized approach to each patient is required.

Looking ahead, we see 3 major fields of action: educating patients before their imaging examination and addressing any remaining concerns they may have during follow-up; ensuring that imaging protocols are optimized and follow the as-low-as-reasonably-achievable principle when applicable; and restricting the overuse of imaging procedures, particularly those with ionizing radiation. All 3 actions require support from various individuals, including imaging experts, medical professionals, technical staff, application specialists from the manufacturers, and hospital administrators.

\section{CONCLUSION}

There are distinct differences between patients and specialists in their evaluation and perception of ionizing radiation, both in general and in a medical context. The perception of patients-as odd as it may seem to expertsforms a strong basis for the decisions that patients make. For that reason, the concepts that patients share with their physicians during informational conversations must be considered before an investigation or therapy can begin.

It is evident that not only patients but many physicians outside nuclear medicine and radiology are laypersons with regard to these specialties. It must be a primary goal of radiologic and nuclear medical professionals to thoroughly and carefully educate future opinion shapers. Imaging experts and clinical staff alike are accountable for selecting an ionizing radiation imaging examination as part of the patient work-up, and they are further responsible for choosing the optimum imaging parameters and protocols.

Furthermore, radiation safety and the role of patient perception with regard to, for example, CT should be investigated in future studies. We think that broadening the scope of investigators to include sociologic and anthropologic aspects would be a fruitful approach.

\section{ACKNOWLEDGMENTS}

We thank Johannes Czernin (Los Angeles) for helpful discussions, advice, and support materials; Ulrike Nichols (London) for translational help and editing; and Robert J. Marlowe (New Jersey) for a critical review of the manuscript. No potential conflict of interest relevant to this article was reported.

\section{REFERENCES}

1. Fazel R, Krumholz HM, Wang Y, et al. Exposure to low-dose ionizing radiation from medical imaging procedures. N Engl J Med. 2009;361:849-857.

2. Dinan MA, Curtis LH, Hammill BG, et al. Changes in the use and costs of diagnostic imaging among Medicare beneficiaries with cancer, 1999-2006. JAMA. 2010;303:1625-1631.
3. Bundesamt für Strahlenschutz. Umweltradioaktivität und Strahlenbelastung im Jahr 2008. Available at: http://dipbt.bundestag.de/dip21/btd/17/007/1700770.pdf. Accessed August 29, 2011.

4. Nickoloff EL, Alderson PO. Radiation exposures to patients from CT: reality, public perception, and policy. AJR. 2001;177:285-287.

5. Brenner DJ, Hall EJ. Computed tomography: an increasing source of radiation exposure. N Engl J Med. 2007;357:2277-2284.

6. Huang B, Law MW, Khong PL. Whole-body PET/CT scanning: estimation of radiation dose and cancer risk. Radiology. 2009;251:166-174.

7. Brix G, Nekolla EA, Nosske D, Griebel J. Risks and safety aspects related to PET/ MR examinations. Eur J Nucl Med Mol Imaging. 2009;36(suppl 1):S131-S138.

8. Berrington de González A, Mahesh M, Kim KP, et al. Projected cancer risks from computed tomographic scans performed in the United States in 2007. Arch Intern Med. 2009;169:2071-2077.

9. Gesundheitsdirektorenkonferenz (GDK). Kombinierte Positronenemissions- und Computertomographie (PET/CT) bei Diagnostik und Staging der Lungentumoren. Available at: http://www.medical-board.ch/fileadmin/docs/public/mb/ Fachberichte/2011-01-31_PET_CT_Kurzfassung.pdf. Accessed August 29, 2011.

10. Eschner W, Schmidt M, Dietlein M, Schicha H. PROLARA: prognosis-based lifetime attributable risk approximation for cancer from diagnostic radiation exposure. Eur J Nucl Med Mol Imaging. 2010;37:131-135.

11. Schindera ST, Nauer C, Treier R, et al. Strategies for reducing the CT radiation dose [in German]. Radiologe. 2010;50:1120, 1122-1127.

12. Baumann BM, Chen EH, Mills AM, et al. Patient perceptions of computed tomographic imaging and their understanding of radiation risk and exposure. Ann Emerg Med. 2011;58:1-7.e2.

13. Shaw LJ, Achenbach S, Chandrashekhar Y, et al. Imaging modalities and radiation: benefit has its risks. JACC Cardiovasc Imaging. 2010;3:550-552.

14. Fischhoff B, Slovic P, Lichtenstein S, Read S, Combs B. How safe is safe enough? A psychometric study of attitudes towards technological risks and benefits. Polit Sci. 1978;9:127-152.

15. Slovic P, Fischhoff B, Lichtenstein S. Rating the risks. Environment. 1979; 21:14-20.

16. Slovic P. Perception of risk. Science. 1987;236:280-285.

17. Slovic P. Perception of risk from radiation. Radiat Prot Dosimetry. 1996;68:165180.

18. Ludwig RL, Turner LW. Effective patient education in medical imaging: public perceptions of radiation exposure risk. J Allied Health. 2002;31:159-164.

19. Bolderston A. Radiotherapy patient education: getting the message across. Can J Med Radiat Technol. 2002;33:15-21.

20. Bolderston A. Mixed messages? A comparison between the perceptions of radiation therapy patients and radiation therapists regarding patients' educational needs. Radiography. 2008;14:111-119.

21. Englander T, Farago K, Slovic P, Fischhoff B. A comparative risk analysis of risk perception in Hungary and the United States. Soc Behav. 1986;1:55-66, 167.

22. Sjöberg L. Risk perception: experts and the public. Eur Psychol. 1998;3:1-13.

23. Greenwald AG, McGhee DE, Schwartz JLK. Measuring individual differences in implicit cognition: the implicit association test. J Pers Soc Psychol. 1998;74: 1464-1480.

24. Mierke J. Kognitive Prozesse bei der indirekten Messung von Einstellungen mit dem Impliziten Assoziationstest. Inaugural dissertation. Available at: http:// deposit.ddb.de/cgi-bin/dokserv?idn $=973922885 \&$ dok_var=d1\&dok_ext $=$ pdf $\&$ filename $=973922885$.pdf. Accessed August 29, 2011.

25. Siegrist M, Keller C, Cousin ME. Implicit attitudes toward nuclear power and mobile phone base stations: support for the affect heuristic. Risk Anal. 2006; 26:1021-1029.

26. Atteslander P, Cromm J, Grabow B, eds. Methoden der empirischen Sozialforschung. 10th ed. Berlin, Germany: Schmidt-Verlag; 2006.

27. Brednich RW. Quellen und methoden. In: Brednich RW, ed. Grundriss der Volkskunde. 3rd ed. Berlin, Germany: Reimer; 2001:73-91.

28. Göttsch S, Lehmann A, eds. Methoden der Volkskunde: Positionen, Quellen, Arbeitsweisen der Europäischen Ethnologie. 2nd ed. Berlin, Germany: Reimer; 2007.

29. Knorr-Cetina K. Die Fabrikation von Erkenntnis: Zur Anthropologie der Naturwissenschaft. Frankfurt am Main, Germany: Suhrkamp; 1984.

30. Flick U, von Kardorff E, Steinke I, eds. Qualitative Forschung: Ein Handbuch. 6th ed. Reinbek, Germany: Rowohlt; 2005.

31. Mayring P. Qualitative Inhaltsanalyse: Grundlagen und Techniken. 8th ed. Weinheim, Germany: Beltz; 2003.

32. Berg E, Fuchs M, eds. Kultur, soziale Praxis, Text: Die Krise der ethnographischen Repräsentation. Frankfurt am Main, Germany: Suhrkamp; 1993.

33. Shrimpton PC, Hillier MC, Lewis MA, Dunn M. National survey of doses from CT in the UK: 2003. Br J Radiol. 2006;79:968-980.

34. Soye JA, Paterson A. A survey of awareness of radiation dose among health professionals in Northern Ireland. Br J Radiol. 2008;81:725-729. 
35. Hall EJ, Brenner DJ. Cancer risks from diagnostic radiology. Br J Radiol. 2008;81:362-378.

36. Romano DH. Self-referral of imaging and increased utilization: some practical perspectives on tackling the dilemma. J Am Coll Radiol. 2009;6:773-779.

37. Lee CI, Haims AH, Monico EP, et al. Diagnostic CT scans: assessment of patient, physician, and radiologist awareness of radiation dose and possible risks. Radiology. 2004;231:393-398.

38. Heyer CM, Peters S, Lemburg S, Nicolas V. Awareness of radiation exposure of thoracic CT scans and conventional radiographs: what do non-radiologists know? [in German]. Rofo. 2007;179:261-267.

39. Westerterp M, van Westreenen HL, Deutekom M, et al. Patients' perception of diagnostic tests in the preoperative assessment of esophageal cancer. Patient Prefer Adherence. 2008;2:157-162.

40. Bastiaannet E, Hoekstra-Weebers JE, Francken AB, Jager PL, van der Jagt EJ, Hoekstra HJ. Perception of burden experienced during diagnostic tests by melanoma patients with lymph node metastases. Melanoma Res. 2009;19:36-41.

41. Freudenberg LS. "You like to turn me into a firefly": subjective concepts of radioactivity in patients before therapy with unsealed radioactive materials [in German]. Volkskunde und Historische Anthropologie. 2001;3:27-44.

42. Freudenberg LS, Beyer T, Bockisch A. Improving perceptions of the quality of service in nuclear medicine. Eur J Nucl Med Mol Imaging. 2003;30:472.

43. Freudenberg LS, Görges R, Bockisch A. "Leuchte ich dann im dunkeln?" Konzepte subjektiver strahlenwahmehmung als wesentlicher faktor zur akzeptanz einer radiojodtherapie. In: Mann K, Weinheimer B, Janssen OE, eds. Schilddrüse 2001: Schilddrüse und Autoimmunität. Berlin, Germany: Walter de Gruyter; 2002:257-265.

44. Freudenberg LS, Beyer T, Muller SP, Görges R, Hopfenbach A, Bockisch A. Evil radioactivity: subjective perception of radioactivity in patients with thyroid disease prior to treatment with radioiodine [in German]. Nuklearmedizin. 2006; 45:229-234

45. Freudenberg LS, Müller SP, Beyer T, Bockisch A. Subjective perception of radioactivity: no change after successful treatment with radioiodine [in German]. Nuklearmedizin. 2009;48:84-88.

46. Erikson K. Radiation's lingering dread. Bull At Sci. 1991;47:34-39.

47. Erikson K. Toxic reckoning: business faces a new kind of fear. Harv Bus Rev. 1990;1:118-126.

48. Weart SR. Nuclear Fear: A History of Images. Cambridge, MA: Harvard University Press; 1998.
49. Smith K. Perception of risks associated with nuclear power. Energy Environment Monitor. 1988;4:61-70.

50. Hendee WR. Personal and public perceptions of radiation risks. Radiographics. 1991;11:1109-1119.

51. Hammick M, Tutt A, Tait DM. Knowledge and perception regarding radiotherapy and radiation in patients receiving radiotherapy: a qualitative study. Eur $J$ Cancer Care (Engl). 1998;7:103-112.

52. Hahn S, Freudenberg LS. Krebs: Nomen est omen? Eine medizin- und kulturhistorische betrachtung zum namen der krankheit. In: Ehninger Gh, ed. Individuelle Therapiemöglichkeiten bei "unbegrenzten Möglichkeiten." Dobersdorf, Germany: Pechstein; 1995:89-99.

53. Sherry I. Nuclear medicine: will I glow in the dark, nurse? Nurs Stand. 2000;14:48-53.

54. Hauser-Schäublin B, Röttger-Rössle B. Differenz und Geschlecht: Neue Ansätze in der ethnologischen Forschung. Berlin, Germany: Reimer; 1998.

55. Stegie R, Stender KH, Gunther D. X-rays in the opinion of the population: a survey of 181 administrative employees [in German]. Radiologe. 1979;19:196-199.

56. Hauser-Schäublin B, Kalitzkus V, Petersen I, Schröder I. Der geteilte Leib: Die kulturelle Dimension von Organtransplantation und Reproduktionsmedizin. New York, NY: Campus; 2001.

57. Franklin S, Ragoné H. Reproducing Reproduction: Kinship, Power, and Technological Innovation. Philadelphia, PA: University of Pennsylvania Press; 1998.

58. Strathern M. Reproducing the Future: Anthropology, Kinship, and the New Reproductive Technologies. New York, NY: Routledge; 2002.

59. Mubeen SM, Abbas Q, Nisar N. Knowledge about ionising and non-ionising radiation among medical students. J Ayub Med Coll Abbottabad. 2008;20:118-121.

60. Gower-Thomas K, Lewis MH, Shiralkar S, Snow M, Galland RB, Rennie A. Doctors' knowledge of radiation exposures is deficient [letter]. BMJ. 2002;324:919.

61. Hall P, Holm LE, Lundell G, Ruden BI. Tumors after radiotherapy for thyroid cancer: a case-control study within a cohort of thyroid cancer patients. Acta Oncol. 1992;31:403-407.

62. D'Haese S, Vinh-Hung V, Bijdekerke P, et al. The effect of timing of the provision of information on anxiety and satisfaction of cancer patients receiving radiotherapy. J Cancer Educ. 2000;15:223-227.

63. Lamszus K, Verres R, Hubene KH. Wie erleben die patienten die strahlentherapie? Strahlenther Onkol. 1994;170:162-168.

64. McNeil BJ, Pauker SG, Sox HC, Tversky A. On the elicitation of preferences for alternative therapies. $N$ Engl J Med. 1982;306:1259-1262. 